\title{
sit \\ Controvérsias científicas ou negação da ciência? A agnotologia e a ciência do clima \\ José Correa Leite
}

\author{
Merchants of doubt. How a handful of scientists obscured the truth \\ on issues from tobacco smoke to global warming \\ Naomi Oreskes \& Eric M. Conway \\ Bloomsbury \\ New York, 2010, 368 págs.
}

Na medida em que se torna determinante da dinâmica da economia e da política, a tecnociência passa a mediar as definições e as tomadas de decisão sobre um número crescente de questões. Ela se torna um campo de batalha de interesses contraditórios, onde o avanço do conhecimento científico amiúde questiona diretamente os poderes estabelecidos. Como a ciência fornece as bases para os discursos mais legítimos da sociedade, aqueles que são questionados por ela têm que reagir contrapondo argumentos e teorias supostamente científicos, mesmo quando não o sejam. $\mathrm{O}$ caso da relação entre o hábito de fumar e o aumento da incidência de câncer é o exemplo clássico, mas a indução da ignorância ou da dúvida sobre temas onde já existe um consenso científico tornouse uma prática comum na sociedade atual. Aleitura de Mooney (2005) e Michaels (2008) permite pôr em discussão dezenas de tópicos de conflito nas mais variadas áreas. Assim, as controvérsias escalam até ganharem a conotação de uma verdadeira guerra cultural no caso da emissão dos gases de efeito estufa, os quais, segundo indicação da própria ciência, produzem o aquecimento global (impacto negado ou questionado pelas indústrias de combustível fóssil e de geração de energia em termoelétricas).

Robert Proctor, historiador da ciência da Universidade de Stanford, cunhou um termo para designar o estudo da negação da ciência com vistas a produzir a dúvida ou a ignorância - em oposição ao estudo do conhecimento pela epistemologia -, a saber, agnotology, que podemos traduzir por agnotologia (do grego agnosis, não conhecimento). O propósito da agnotologia seria "promover o estudo da ignorância, desenvolvendo ferramentas para compreender como e porque várias formas de conhecimento não 'emergiram', ou desapareceram, ou foram retardadas ou negligenciadas por longo tempo, para melhor ou para pior, em vários pontos da história" (Proctor \& Schiebinger, 2008, p. vii). 
Merchants of doubt é um livro que, pondo-se na perspectiva da agnotologia, ajuda a reposicionar a forma como são tratados os debates e as controvérsias na ciência do clima. Há um amplo acordo entre os cientistas sobre as raízes antropogênicas do atual aquecimento global. O estudo de Cook e colaboradores, citado por Benestad (2013, p. 454), analisou os resumos de 12 mil artigos sobre o tema, constatando que $97 \%$ deles apoiam o consenso expresso nos relatórios do Painel Intergovernamental sobre $\mathrm{Mu}$ dança Climática (Intergovernamental Panel on Climate Change - IPCC). Uma década antes, um estudo dos resumos de 928 artigos, conduzido por Naomi Oreskes (2004), não tinha localizado nenhum trabalho que se contrapusesse ao reconhecimento das causas humanas do aquecimento global recente ( $25 \%$ deles, estudos de metodologia ou de paleoclimatologia, não se posicionavam sobre o tema). Mas as pesquisas de opinião mostram um enorme hiato entre esse consenso e a forma como a população trata o assunto, em especial nos Estados Unidos, onde Doran e Zimmerman (2009) informam acerca de pesquisas que apontam que apenas $52 \%$ da população acredita que 0 aquecimento global tem causas antropogênicas e que apenas $47 \%$ acreditam que exista um consenso na comunidade científica sobre isso.

Essa ignorância não é fruto do acaso, mas resultado de uma intervenção política e cultural ampla, que tem como objetivo obscurecer a informação e a compreensão da população sobre o tema, do mesmo modo que a indústria do tabaco criou, durante meio século, dúvidas sobre as pesquisas científicas que estabeleciam a conexão entre o tabaco e o câncer. E, no caso dos Estados Unidos, essa intervenção esteve concentrada, por três décadas, na autoridade de um pequeno grupo de cientistas.

\section{O ataque ao Painel Intergovernamental sobre Mudanças Climáticas, A ESTRATÉGIA DO TABAGO E OS MERGADORES DA DÚVIDA}

Naomi Oreskes, historiadora da ciência da Universidade de Harvard, e Eric Conway, historiador vinculado ao Laboratório de Propulsão a Jato da NASA, retraçam, em Merchants of doubt, sete disputas envolvendo a ciência nos Estados Unidos, revelando gradualmente os nexos entre os diferentes processos de negação da ciência por cientistas de renome. Os autores partem em sua narrativa, na introdução da obra, do ataque sofrido por Benjamin Santer, um cientista do clima, depois da divulgação do segundo relatório do IPCC em 1995. Santer foi o responsável por fechar o oitavo capítulo do relatório, intitulado "Detecção da mudança climática e atribuição de causas". Frederick Seitz - antigo presidente da National Academy of Sciences (NAS) entre 1962 e 1969 - acusou Santer, no jornal Wall Street, de ter modificado arbitrariamente a redação final do capítulo para ressaltar a responsabilidade humana no aquecimento global. 
Seguiram-se muitos outros artigos acusatórios de Seitz e seus associados, sempre atacando Santer por fraude, principalmente em veículos empresariais. Ele, porém, apenas incorporou em seu texto final as contribuições que surgiram no processo de revisão por seus pares da versão anterior do capítulo, característica normal no processo de produção científica contemporâneo, fato bem conhecido por Seitz e outros críticos do IPCG, mas ignorado em seus ataques pelos jornais. Os principais responsáveis pelo IPGG, a Associação Meteorológica Americana e, por fim, um grupo de 40 climatologistas de destaque enviaram cartas ao jornal Wall Street em defesa de Santer, mas o jornal só publicou discretos extratos delas, enquanto dava destaque às acusações. Tratava-se não de uma controvérsia científica, mas de um ataque político às conclusões do IPCG, que se desdobrava em um ataque pessoal à reputação de Santer.

Anos depois, Santer descobriu que dois dos seus mais agressivos acusadores, Fredrick Seitz e Fred Singer, tinham estado à frente de um programa organizado pela indústria do tabaco para desacreditar as evidências científicas ligando o fumo ao câncer, onde aplicavam a antiga estratégia do setor de "manter a controvérsia viva" para safar-se dos processos judiciais e adiar a adoção de medidas restritivas ao fumo, a mesma estratégia que eles aplicavam para evitar restrições à emissão de carbono frente ao aquecimento global.

A "estratégia do tabaco" era empregar cientistas para levantarem dúvidas sobre a relação entre o hábito de fumar e os riscos para a saúde. A extensa pesquisa de Oreskes e Conway localizou o núcleo dos executores dessa estratégia no Instituto George C. Marshall, constituído em 1984. Seus fundadores eram três físicos aposentados, Frederick Seitz (1911-2008), Robert Jastrow (1925-2008) e William Nierenberg (19192000). Como Siegfried (Fred) Singer (1924), outro expoente da "estratégia do tabaco", eles exerceram funções de destaque no período da guerra fria.

Os quatro físicos aposentados são os principais “mercadores da dúvida”, mantendo fortes vínculos com os círculos conservadores (Bush pai os chamou de "meus cientistas") e com o mundo empresarial. Foram responsáveis durante mais de duas décadas pela tática de "manter a controvérsia viva", repetindo-a em sucessivos debates, sem levar em consideração o consenso científico que se constituía sobre as temáticas.

Os mercadores da dúvida utilizavam suas credenciais científicas passadas para obscurecerem as diferenças entre as controvérsias científicas e as disputas de opinião na mídia. A Comissão Federal de Comunicações (FCG) tinha introduzido, em 1949, a "doutrina da equidade" (fairness), pela qual os veículos de radiodifusão deveriam dedicar tempo à discussão de temas controversos e apresentar de maneira equilibrada as posições contrastadas. Essa doutrina enraizou-se na mídia estadunidense e esses cientistas recorriam a ela toda vez que queriam veicular suas posições. 
Mas o contraditório pode representar a negação do debate científico, se a contradição não representa posições respaldadas por pesquisadores ativos nas áreas em discussão e ignora ou recusa, sem provas, o consenso científico estabelecido. James Hansen (2013) lamenta ter que discutir ciência com advogados que utilizam argumentos de tribunal para "ganharem" a discussão. Stephen Schneider (cf. 2009, p. 203) lamenta a tática persistente de distorção, ataques pessoais, falsas notícias, interpretações unilaterais pagas por lobbies e corporações "e outras violações da ética da mídia". Essas controvérsias visam retardar o desdobramento do consenso científico em regulação e políticas públicas, nada tendo a ver com debates científicos ou com uma postura de ceticismo. Essas controvérsias são a negação da ciência e uma maneira de afirmar a pseudociência travestida de ciência, remetendo para o terreno da agnotologia.

\section{2 “A DÚVIDA É NOSSO PRODUTO”}

O primeiro capítulo da obra de Oreskes e Conway mostra como a indústria do tabaco foi a inventora e a mais hábil praticante da estratégia de promover a dúvida quanto aos resultados da ciência. Estudos científicos tornaram evidente a conexão entre o fumo e o câncer nos anos 1950. Em 1953, a American Tobacco, Benson \& Hedges, Philip Morris e U.S. Tobacco contrataram a firma de relações públicas Hill \& Knowlton para defender seu produto e montaram um Comitê de Pesquisa da Indústria do Tabaco para fornecer argumentos que desafiassem a crescente evidência científica de que fumar prejudicava a saúde. Esse comitê iniciou encontros com dirigentes da mídia norte-americana, forneceu-lhes estudos que desmentiam as acusações, contratou um famoso geneticista que sustentava que a causa do câncer era uma fraqueza genética e distribuiu folhetos sobre a "controvérsia do cigarro" para médicos, responsáveis pela mídia e políticos dos EUA. Nada menos do que 77 das 79 faculdades de medicina do país participavam do programa patrocinado pela indústria.

Mas as evidências científicas acumulavam-se. Em 1964, um estudo intitulado "Fumo e saúde" confirmava a conexão entre fumar e a incidência de câncer. Em 1967, mais de dois mil estudos já reforçavam a conclusão de que fumar era prejudicial à saúde. Em 1969, a FCG baniu a propaganda de cigarros da televisão e do rádio. Mas a indústria duplicou suas despesas no apoio a médicos e hospitais, passando de US $\$ 50$ milhões para US $\$ 100$ milhões por ano. A estratégia de negar os resultados científicos continuava funcionando. Dos 125 processos enfrentados pela indústria entre 1954 e 1979, apenas nove foram a julgamento e a indústria ganhou todos. Apesar disso, a indústria do tabaco contratou, em 1979, Frederick Seitz para desacreditar o consenso científico que já 
era esmagador. Sua estratégia de manter a controvérsia viva, questionando o nexo entre o hábito de fumar e o câncer, continuou eficaz ainda por algum tempo.

A natureza probabilista das afirmações da epidemiologia foi trabalhada pela indústria do cigarro junto à opinião pública, mediante um hábil uso da dúvida com base no próprio caráter hipotético da ciência. Um executivo da indústria escreveria, em 1969, que "a dúvida é nosso produto". Foi somente na virada para os anos 2000 que a indústria do tabaco foi derrotada nos tribunais, graças à divulgação de documentos internos e de seus próprios estudos, que mostravam os danos do cigarro à saúde, estudos que ela ocultou por décadas, contribuindo para a morte de milhões de pessoas.

\section{Guerra nas estrelas, inverno nuglear E o Instituto Marshall}

Seitz já tinha, então, desdobrado suas intervenções. Como mostram Oreskes e Conway no segundo capítulo do livro, ele concentra cada vez mais atenção, na década de 1980, na defesa do projeto "guerra nas estrelas".

Nas décadas de 1960 e 1970, a doutrina da guerra nuclear entre os estrategistas militares era conhecida como a da "destruição mutuamente assegurada" (MAD), que significava que nenhuma das duas superpotências poderia utilizar suas armas nucleares contra a outra ou provocar um incidente que levasse a seu uso. Todavia, quando Reagan assume a presidência dos Estados Unidos, em 1980, lança a "iniciativa de defesa estratégica" (SDI, também conhecida como "guerra nas estrelas"), visando desenvolver armas a serem colocadas em órbita, capazes de destruir os mísseis inimigos e garantir a vitória em uma guerra nuclear. Robert Jastrow era, com Edward Teller, um dos campeões na defesa desse projeto, mas enfrentava uma oposição liderada por Carl Sagan e Hans Bette, que era majoritária na comunidade científica e que, depois do acidente na usina nuclear de Three Miles Island em 1979, estava em sintonia com um movimento antinuclear muito ativo e disseminado.

De nada adiantava um sistema antimísseis que abatesse 90\% dos agressores, já que os restantes 10\% eram suficientes para destruir o país. A estratégia de evitar a guerra através da garantia da "destruição mutuamente assegurada" continuava a ser a única opção racional. Contudo, a polêmica na comunidade científica girava em torno do conceito de "inverno nuclear". As especulações que emergiram na época, segundo as quais o choque de um meteorito com a Terra teria extinto os dinossauros, alimentaram discussões sobre o impacto climático de uma guerra nuclear. No Centro de Pesquisa Ames da NASA, cientistas utilizaram modelos de computador para calcular o impacto do uso de armas nucleares sobre o clima. O resultado foi a projeção de que um conflito pode- 
ria lançar na atmosfera resíduos que cobririam o planeta e produziriam uma queda na temperatura de $35^{\circ} \mathrm{C}$, um inverno nuclear que varreria quase toda a vida do planeta. $\mathrm{O}$ artigo que apresentava esses resultados, assinado por Sagan e outros, tornou-se foco de um debate nacional. Estudos posteriores no Centro Nacional de Pesquisas Atmosféricas em Boulder, no Colorado, apontaram para uma queda menor, entre $10^{\circ} \mathrm{C} \mathrm{e} 20^{\circ}$ C, mas a física aumentou a probabilidade da hipótese do inverno nuclear.

É nesse contexto que Jastrow lança a iniciativa do Instituto George C. Marshall para combater o que considerava ambientalistas pacifistas manipulados pelos soviéticos. Seus apoiadores recorreriam aos mesmos métodos da indústria do cigarro para travar o debate contra os defensores da ideia do inverno nuclear. Oreskes e Conway afirmam que esse episódio dá início ao movimento contrário à ciência dos conservadores norte-americanos. Até o governo Reagan, havia um consenso bipartidário quanto à importância da ciência e da tecnologia para o progresso e a defesa nacional, mesmo em temas como o meio-ambiente, sendo que a Agência de Proteção Ambiental (EPA) e a moderna legislação ambiental do país foram criadas pela administração Nixon. Mas, para os falcões da guerra fria, isso se rompe, nos anos 1980, em duas frentes. De um lado, quando a maior parte dos cientistas, que já tinham questionado o envolvimento no Vietnã, passam a colocar em questão a nova política frente à URSS. De outro lado, com as crescentes políticas de regulação, principalmente ambiental, que buscavam solucionar problemas criados pelo livre mercado em um momento em que o neoliberalismo retomava a ideologia do estado mínimo e valorizava a desregulamentação.

\section{Chuva ÁGida, Buraco na Gamada de ozônio E fumantes Passivos}

Um contencioso estava em curso com o Canadá sobre as chuvas ácidas que atingiam as florestas canadenses (tema do terceiro capítulo do livro). Essas chuvas provinham das emissões de dióxido de enxofre das usinas termoelétricas dos EUA, segundo era indicado até mesmo pela NAS. O governo Reagan apontou Nierenberg para coordenar o painel de pares que deveria apresentar o parecer final sobre o assunto - oito dos demais nove membros do painel seriam indicados pela NAS e pela Academia Nacional de Engenharia; o nono indicado pela Casa Branca era Fred Singer. Na década de 1960, Singer tinha sido um ambientalista, mas na década de 1980 sua posição valorizava antes de tudo a inovação tecnológica impulsionada pelo livre mercado. Nierenberg e Singer fizeram crer que o painel estava dividido em seus pontos de vista, ainda que a ampla maioria considerasse que alguma medida tinha de ser tomada para conter a emissão de dióxido de enxofre das termoelétricas, que as amostras de água de chuva colhidas evidenciavam ser a fonte das chuvas ácidas. Além disso, a Casa Branca reescreveu o rela- 
tório do painel com o aval de Nierenberg. Ele não reconhecia a necessidade da instalação de filtros nas usinas, pois isso encarecia a geração de energia e reduzia a rentabilidade das empresas. O argumento era, novamente, que existiam dúvidas sobre a relação entre a poluição das usinas e as chuvas ácidas.

O quarto capítulo trata do debate em torno do buraco na camada de ozônio. Em setembro de 1976, um painel da NAS confirmou a relação entre a emissão de clorofluorcarbonos (CFCs) e a degradação da camada de ozônio, abrindo uma discussão ampla sobre a necessidade de proibir o uso dos CFCs, cuja utilização começou a ser rapidamente reduzida nos EUA. Quando um buraco na camada de ozônio sobre a Antártida foi descoberto em 1985, uma convenção patrocinada pela ONU propôs uma restrição global ao uso dos CFCs, levando à assinatura do Protocolo de Montreal em 1987, revisto em 1990 para banir qualquer emissão na atmosfera. Mas não sem a objeção de Singer, então cientista-chefe do Departamento de Transportes. Ele afirmava inicialmente que o buraco era um problema temporário, e, depois, que seria causado pelo resfriamento da estratosfera em virtude de uma variabilidade natural do clima, não exigindo nenhuma regulação da produção de CFGs. A intervenção de Singer visava desconstruir a ideia de que havia uma posição da comunidade científica sobre o tema, mas aqui até mesmo a multinacional Du Pont aceitou a posição e abandonou a produção de CFGs. Ainda assim, quando, em 1995, Molina e Crutzen ganharam o Nobel de química por essa descoberta, Singer escreveu que se tratava de uma "declaração política". A opinião pública sueca até mesmo apoiaria uma "hipotética taxa sobre o carbono para reverter um aquecimento do clima global que ainda não foi detectado (...). Sinteticamente, o país está tomado de uma histeria ambiental coletiva" (Singer apud Oreskes \& Conway, 2010, p. 133).

Voltando ao tema do tabaco, no quinto capítulo da obra, Oreskes e Conway lembram que a EPA divulgou, em 1992, um relatório sobre “os efeitos na saúde respiratória do fumo passivo", atribuindo três mil mortes de câncer do pulmão por ano ao fumo passivo, bem como o agravamento dos casos de bronquite, pneumonia e asma de centenas de milhares de crianças. Uma nova frente de luta abria-se para os fabricantes de cigarros. Fred Singer empreende a resposta da indústria do tabaco através de um ataque sistemático à EPA. Ele e Fred Seitz encabeçam uma campanha de denúncia de uma ciência que afirmam estar baseada no exagero, na distorção e na fraude, e a qual corresponderia, de fato, a quase toda a ciência ambiental e a boa parte da epidemiologia e da saúde pública, que prescreviam medidas de regulação estatal, para eles sinônimo de socialismo.

Os "mercadores da dúvida" usam o grau de incerteza presente em todo estudo estatístico para questionar qualquer conclusão que questione as práticas da livre iniciativa. 


\section{Organizar o ATRAso dA RESPosta NA QUESTÃo Do GLIMA}

No capítulo 6, Oreskes e Conway lembram o alerta, dado por Roger Revelle em 1965 e apoiado nas medições de Keeling, para uma possível elevação da temperatura da Terra pelas emissões de dióxido de carbono. Seu relatório afirmava que "pelo ano 2000 haverá $25 \%$ mais $\mathrm{CO}_{2}$ na nossa atmosfera do que no presente [e] isso modificará o equilíbrio térmico da atmosfera tão extensamente que mudanças marcantes no clima (...) poderão ocorrer" (p. 170). Nos anos 1970, modelos climáticos, alimentados por dados de satélites, já confirmavam essas previsões.

A NAS conduziu, em 1977, um estudo para rever o estado da discussão. Encabeçado por Jule Charney, do MIT, ele se apoiou em um modelo climático de três dimensões construído por Syukuro Manabe e James Hansen, mostrando que se dobrasse a quantidade de $\mathrm{CO}_{2}$ na atmosfera, teríamos um aumento de temperatura entre $1,5^{\circ} \mathrm{Ce}$ $4^{\circ} \mathrm{C}$, provavelmente de $3^{\circ} \mathrm{C}$. Se as emissões fossem maiores, provavelmente o aumento de temperatura seria maior do que $3^{\circ} \mathrm{C}$. Quando isso ocorreria? Não se podia oferecer uma resposta segura, porque isso dependeria de quanto calor fosse absorvido pelos oceanos; eles poderiam funcionar como sumidouro de calor por várias décadas.

As conclusões perturbadoras para os políticos deram origem à tática que Oreskes e Conway denominam de "organizar o atraso". Foram encomendados dois estudos para a NAS. O primeiro, liderado pelo economista Thomas Schelling e com a participação de Nierenberg, apresentou suas conclusões em abril de 1980. "Face às incertezas, controvérsias e vínculos complexos envolvendo a questão do dióxido de carbono, e a possibilidade de que algumas das maiores incertezas sejam reduzidas em uma década, parece à maioria de nós que a ênfase de médio prazo deve ser na pesquisa, com o perfil político mais baixo possível (...) Hoje não conhecemos o suficiente sobre a maioria destas questões" (p. 175). Esse trabalho foi duramente criticado pelo chefe do escritório de pesquisa climática da NAS, que publicou o artigo "Energia e clima: problema para hoje, não para amanhã”.

O segundo estudo foi dirigido por Nierenberg, e diferente dos demais estudos da NAS, não foi coletivo, mas dividido em dois blocos, cinco capítulos dos cientistas naturais (que reafirmaram as posições do relatório de Jule Charney) e dois capítulos sobre emissões e impactos climáticos de economistas (que foram na linha do relatório Schelling). Por decisão de Nierenberg, os capítulos de abertura e conclusão foram os dos economistas, neutralizando o impacto do relatório, divulgado em 1983.

A discussão só foi reaberta em 1988, de um lado com a criação do IPCC, formado para monitorar o buraco na camada de ozônio e, de outro lado, com a declaração de James Hansen de que o aquecimento global antropogênico tinha começado. Hansen testemunha no congresso norte-americano com ampla cobertura da mídia e o tema do 
aquecimento global volta a atrair a atenção também dos mercadores da dúvida. Com o colapso da URSS, o Instituto Marshall decide dirigir suas baterias contra os ambientalistas "alarmistas". Ele divulga um contrainforme para a Casa Branca em que não nega o aquecimento global, mas culpa uma variação natural do Sol por isso. Ainda assim, o novo presidente dos EUA, George Bush, enviou seu secretário de estado, James Baker, para a reunião inaugural do IPCG, em 1989. Em maio de 1990, o IPCC divulgou o primeiro relatório sobre o tema, envolvendo em sua elaboração mais de 300 cientistas de 25 países. Sua conclusão foi que o uso irrestrito de combustíveis fósseis produzirá uma taxa de aumento da temperatura média global durante o próximo século de $0.3^{\circ} \mathrm{C}$ por década, maior do que o visto nos últimos 10.000 anos. O IPCC também afirmava que o peso disso era muito maior do que o das variações na temperatura do Sol. Nierenberg insistia que a temperatura em 2100 não seria mais do que $1^{\circ} \mathrm{C}$ maior, como afirmou no Congresso Mundial do Petróleo, em 1991. Mas isso não impediu que Bush comparecesse à Cúpula da Terra no Rio de Janeiro em 1992 e firmasse a Convenção das Nações Unidas sobre Mudanças Climáticas (apenas uma declaração de intenções, mas significativa).

\section{O NEOLIBERALISMO E AS MUDANÇAS GLIMÁTICAS}

Nesse momento, a narrativa de Oreskes e Conway retorna ao tema da divulgação do segundo relatório do IPCG, em 1995, e do ataque a Ben Santer. Na elaboração do relatório final, durante a plenária com os representantes dos governos e os lobbies, para lançar o segundo relatório do IPCG acordou-se a seguinte formulação no sumário: “o equilíbrio das evidências sugere que há uma influência humana discernível sobre o clima" (p. 205). Isso representava uma consolidação do consenso na comunidade dos cientistas do clima. Já vimos as consequências disso para Santer. Mas a contundência com que os negacionistas retrucaram e consolidaram uma posição nos EUA dão razão a Hansen e Schneider.

Um sétimo capítulo é dedicado ao ataque revisionista contra Rachel Carson, quase meio século depois da denúncia da bióloga contra o surgimento de "primaveras silenciosas" conduzir ao banimento do uso do DDT. Os fundamentalistas de mercado atacam Carson, a fundadora do ambientalismo como movimento político, afirmando que o uso do DDT era seguro e sua proibição foi uma tragédia para os países pobres. Ao criticarem Raquel Carson, os conservadores pretendiam atingir o ecologismo em conjunto. Do mesmo modo que a chuva ácida, o fumo passivo, o buraco no ozônio e o aquecimento global, o DDT impõe enormes custos externos à sociedade através da destruição de ecossistemas e sua proibição evidencia falhas do mercado, que exigem a in- 
tervenção governamental. Mas reconhecer que os subprodutos da civilização industrial estão destruindo o ambiente global é inaceitável para os falcões da guerra fria.

No final, os autores lembram que, embora a liberdade de imprensa seja fundamental para a democracia, a fragmentação da opinião pública nivela as diferentes posições, embora elas não tenham todas o mesmo valor. Isso não ajuda a fortalecer a consciência pública. E, no caso das questões de mérito científico, as regras da produção de conhecimento não são as da democracia, mas aquelas que permitem trabalhar a partir das evidências. "Manter a controvérsia" ou "manter o debate vivo" pode ser e tem sido transformado na negação da ciência. Muitos outros temas podem ser levantados, como o debate de fundamentalistas religiosos contra a teoria da evolução, a relação entre HIV e AIDS, o impacto dos agrotóxicos ou dos transgênicos sobre a saúde e o ambiente, o uso de células tronco etc. Criaram-se inúmeros "boletins, revistas e jornais - incluindo jornais com revisão explícita pelos pares - nos quais os resultados de pesquisas patrocinadas pela indústria podiam ser difundidos, publicados e, então, citados como se fossem independentes" (p. 24.3). Mas isso é, normalmente, o embate de um simulacro da ciência contra a ciência, não uma controvérsia científica. Os cientistas, cujo trabalho é analisado por Oreskes e Conway, trouxeram para dentro das disputas científicas as práticas dos escritórios de advocacia, das relações públicas e da publicidade, bem como das campanhas políticas (cf. p. 274).

O epílogo da obra de Oreskes e Conway intitula-se "Uma nova visão da ciência". Os autores mostram que os mercadores da dúvida foram bem sucedidos porque a visão hegemônica da ciência, difundida pela mídia, é falsa.

Merchants of doubt é uma importante contribuição para o debate em torno das questões do clima e do aquecimento global. Embora não tenhamos focado a atenção nisso, há, naturalmente, muitas controvérsias científicas reais nesse terreno complexo. Mas o primeiro passo para podermos adentrar por esse território é mapearmos quais controvérsias colocam-se no terreno da ciência e quais estão fora dele, remetendo para a agnotologia.\$

Agradecimentos. A resenha aqui publicada faz parte da pesquisa viabilizada pela bolsa de pós-doutorado da Fapesp junto ao Projeto Temático 2011/51614-3, "Gênese e significado da tecnociência: Das relações entre ciência, tecnologia e sociedade".

José Correa Leite

Faculdade de Comunicação, Fundação Armando Álvares Penteado, São Paulo, Brasil. jcleite@dglnet.com.br 


\section{Scientific controversies or denial of science? Agnotology and climate science}

\section{REFERÊNGIAS BIBLIOGRÁFIGAS}

Benestad, R.E. et al. Agnotology: learning from mistakes. Earth System Dynamics Discussion, 4, p. 451505, 2013. Disponível em: <www.earth-syst-dynam-discuss.net/4/451/2013/ doi:10.5194/esdd-4451-2013>. Acesso em: 20 jan. 2014.

Doran, P. T. \& Zimmerman, M. K. Examining the scientific consensus on climate change. Eos, Transactions American Geophysical Union, 90, p. 22-3, 2009.

Hansen, J. Tempestades de meus netos. Mudanças climáticas e as chances de salvar a humanidade. São Paulo: Senac, 2013.

Houghton, J. T.; Jenkins, G. J. \& Ephraim, J. J. (Ed.). Intergovernmental panel on climate change, climate change: the IPCC scientific assessment. Cambridge: Cambridge University Press, 1990. (IPCG1). Disponível em: <http://www.ipcc.ch/publications_and_data/publications_ipcc_first_assessment_1990_ wg1.shtml>. Acesso em: 20 jan. 2014.

Houghton, J. T. et al. (Ed.). Intergovernmental panel on climate change, climate change: the science of climate change. Contributions by working group 1 to the second IPCC assessment report. Cambridge: Cambridge University Press, 1996. (IPCC2). Disponível em: <http://www.ipcc.ch/ipccreports/sar/wg_I/ipcc_sar_ wg_I_full_report.pdf $>$. Acesso em: 20 jan. 2014.

Michaels, D. Doubt is their product: how industry's assault on science threatens your health. London: Oxford University Press, 2008.

Mooney, C. The republican war on science. New York: Basic Books, 2005.

Oreskes, N. The scientific consensus on climate change. Science, 3०6, p. 1686, 2004.

Proctor, R. N. \& Schiebinger, L. (Ed.). Agnotology: the making and unmaking of ignorance. Palo Alto: Stanford University Press, 2008.

SchneIder, S. H. Science as contact sport: inside the battle to save Earth's climate. Washington: National Geographic, 2009. 